\title{
Evaluation of Hemodynamic Changes and Respiratory Physical Findings in Patients with Pulmonary Embolism
}

Masome rabieepour ${ }^{1}$, Khalil Ansarin ${ }^{1}$, Mohamad Reza Ghafari ${ }^{1 *}$, Morteza Ghojazadeh ${ }^{2}$

1. Tuberculosis and lung Disease Research Center, Tabriz University of Medical Sciences, Tabriz, Iran

2. Liver and Gastrointestinal Disease Research Center, Tabriz University of Medical Sciences, Tabriz, Iran

\begin{abstract}
Introduction: Pulmonary thromboembolism (PTE) is a potentially fatal disease with nonspecific symptoms and signs. Patients with Pulmonary embolism often have dyspnea, chest pain, haemoptysis, tachycardia tachypnea and respiratory physical finding including hypoxia and decreased $\mathrm{ETCO}_{2}$. Daily patients with Pulmonary embolism are very few in hospital course and we aimed to determine clinical and paraclinical findings in hospital pulmonary embolism patients.

Methods: we assessed in hospital course of 104 patients with pulmonary embolism with symptom (dyspnea, chest pain, and hemoptysis) and signs (tachypnea, tachycardia, DVT signs, blood pressure) and respiratory physical findings $\left.\left(\mathrm{PO}_{2}, \mathrm{ETCO}\right)_{2}\right)$.

Results: majority of patients had risk factor for PTE; the most common was cancer. $21.2 \%$ of patients had apparent DVT in Doppler sonography. Isolated dyspnea (38\%), chest pain with and without hemoptysis (60\%) and syncope (2\%) were observed in patients. Mean duration of dyspnea resolution was 3.4 days. Mean duration of chest pain resolution was 1.76 days. Mean duration of hemoptysis resolution was 2 days. $64.4 \%$ of the patients were hypoxic and mean duration of hypoxic resolution was 2.63 days. Mean duration of tachycardia resolution was 2.37 days. No relation was observed between size of PTE and mortality or hypotension and $\mathrm{PO}_{2}$. Mean $\mathrm{ETCO}_{2}$ was $23 \pm 2 \mathrm{mmHg}$ and $86.5 \%$ of patients had $\mathrm{ETCO}_{2}$ lower than 28 . Mean duration of $\mathrm{ETCO}_{2}$ resolution was 3.6 days. Most common physical finding that resolved later than others was $\mathrm{ETCO}_{2}$. In $32.7 \%$ of patients, $\mathrm{ETCO}_{2}$ did not resolve.
\end{abstract}

Key words: Pulmonary thromboembolism; Tachycardia; Tachypnea; Hemoptysis; Hypoxic; ETCO2

Research Institute of Tuberculosis and Lung Disease, Imam Reza Hospital, Tabriz University of Medical Sciences, Tabriz, Iran

E-mail: mohammadrezaghaffary@gmail.com

Receive date: 2014-05-06 | Accept date: 2014-05-21 | Publish date:

2014-06-08 DOI: 10.7575/aiac.abcmed.14.02.02.12 


\section{Introduction}

Pulmonary thromboembolism (PTE) is a potentially fatal disease with nonspecific symptoms and signs (1). Patients with PTE often have symptoms including dyspnea, chest pain, haemoptysis, leg pain, and palpitation and signs including tachycardia, tachypnea, leg swelling, fever and respiratory physical findings including hypoxia and decreased $\mathrm{ETCO}_{2}$ (2). Pleuritic chest pain indicates of small PTE. The most common cause of hypoxia is alterations in ventilation/perfusion balance and regional bronchoconstriction and change in surfactant results in arterial hypoxia (3). Hyperventilation almost usually occurs due to increase in dead space as the result of alveolar hypocapnia and decrease in $\mathrm{ETCO}_{2}$ in expiration air of the patients with pulmonary embolism (4). Rumpf et al. showed that $\mathrm{ETCO}_{2}$ above $28 \mathrm{mmHg}$ with sensitivity of $92.6 \%$ excludes PTE (5). Timothy and Morris showed that most rapid resolution of large pulmonary embolism was documented in $51 \mathrm{hr}$ and more gradually for the next 4 to 8 weeks (1). There are very few studies on the hospitalized patients with PTE and we aimed to determine the clinical and paraclinical course in hospitalized PTE patients.

\section{Materials and methods}

Between May 2011 and October 2012, this prospective cohort observational study was performed in hospitalized patients (Pulmonology ward of Imam Reza hospital, Tabriz, Iran). All consecutive patients presented with clinically suspected pulmonary embolism and with documented CT-angiography were included. Exclusion criteria were: patients with heart failure and other pulmonary or renal diseases. We assessed in hospital course of 104 patients with PTE documented with CTangiography. Selected symptoms for PTE were dyspnea, chest pain, and hemoptysis and signs were tachypnea, tachycardia, DVT signs, and blood pressure. Respiratory physical findings were $\mathrm{PO}_{2}, \mathrm{ETCO}_{2}$.

\section{Results}

Mean age of patients was 53.6 years with a mortality rate of $7.6 \%$ and mean duration of hospital stay of 6.8 days which was lower than previous studies. Majority of the patients (75\%) had risk factors for PTE; the most common was cancer (19.2\%). 21 patients had apparent DVT in Doppler sonohraphy (21.2\%). Isolated dyspnea (38\%), chest pain with and without hemoptysis (60\%) and syncope (2\%) were observed in patients. 67 patients had tachycardia (64.4\%) and tachypnea and chest were reported in $92.3 \%$ and $54 \%$ of the patients, respectively. Hemoptysis and dyspnea were seen in $23.1 \%$ and $81 \%$ of the patients, respectively. $17.3 \%$ of patients in our study had massive PTE in their CT-angiography reports.

Clinical course patients: mean duration of dyspnea resolution was 2.44 days. Mean duration of chest pain resolution was 1.76 days. Mean duration of hemoptysis resolution was 2 days. $64.4 \%$ of the patients were hypoxic. Mean duration of hypoxic resolution was 2.63 days. Mean duration of tachycardia resolution was 2.37 days. In our study, no relation was observed between the size of PTE and mortality and hypotension and $\mathrm{PO}_{2}$. Mean $\mathrm{ETCO}_{2}$ of the patients was $23 \pm 2 \mathrm{mmHg}$ and $86.5 \%$ of patients had $\mathrm{ETCO}_{2}$ lower than 28 which was more frequent than hypoxia. Mean duration of $\mathrm{ETCO}_{2}$ resolution was 3.6 days. Most common physical finding that resolved with delay was $\mathrm{ETCO}_{2}$. In 34 patients (32.7\%), $\mathrm{ETCO}_{2}$ did not resolve.

\section{Discussion}

This study is the first study to evaluate the hemodynamic changes and respiratory physical findings in patients with PTE. The overall in- 
hospital mortality in our study was $7.6 \%$ that was lower than other centers. Mean hospital stay was 6.8 days that was lower than other retrospective studies (2). $21.2 \%$ of patients in our study had DVT in Doppler sonography which was higher than other studies (5). Isolated dyspnea, chest pain with or without hemoptysis and hypotension were observed in $38 \%, 60 \%$ and $2 \%$ of the patients, respectively; the amounts were $25 \%, 60 \%$ and $10 \%$, in a retrospective study, respectively. Mean duration of chest pain resolution was 1.76 days and mean duration of tachycardia resolution was 2.37 days. In our study, mean duration of tachypnea resolution was 4.4days. In our study, no relation was detected between size of PTE and mortality or hypotension and $\mathrm{PO}_{2}$ which was similar to other studies (2). In our study, hypoxia was seen in $64.4 \%$ of the patients that was lower than retrospective studies (85-90\%)
(2). Mean duration of hypoxia resolution was 2.63 days. In our study, mean $\mathrm{ETCO}_{2}$ was $23 \pm 2$ $\mathrm{mmHg}$ while; in another retrospective study, it was $25 \pm 2 \mathrm{mmHg}$ and $86.5 \%$ of patients in our study had $\mathrm{ETCO}_{2}$ below $28 \mathrm{mmHg}$; while, in a retrospective study, $92.6 \%$ had $\mathrm{ETCO}_{2}$ below 28 $\mathrm{mmHg}$ (5). In our study, 34 patients of 104 patients did not experience $\mathrm{ETCO}_{2}$ resolution.

\section{Conclusion}

$\mathrm{ETCO}_{2}$ is much more important than hypoxia in PTE patients and it is the only physical finding that does not resolve throughout the hospital stay of patients. Perhaps these patients are the ones that develop pulmonary hypertension in the future; the confirmation of this hypothesis, however, would require further future studies.

\section{References}

1. Timothy A Morris, Peter F Fedullo (2010). Pulmonary Thromboembolism in Murray \& Nades textbook of Respiratory medicine, volume2, 5th edition. Saunders, United States of America. Page 1186-1191.

2. Jaff MR, McMurtry MS, Archer SL, Cushman M, Goldenberg N, Goldhaber SZ, Jenkins JS, Kline JA, Michaels AD, Thistlethwaite P, Vedantham S, White RJ, Zierler BK; American Heart Association Council on Cardiopulmonary, Critical Care, Perioperative and Resuscitation; American Heart Association Council on Peripheral Vascular Disease; American Heart Association Council on Arteriosclerosis, Thrombosis and Vascular Biology. Management of massive and submassive pulmonary embolism, iliofemoral deep vein thrombosis, and chronic thromboembolic pulmonary hypertension: a scientific statement from the American Heart Association. Circulation. 2011; 26;123(16):1788-830.

3. Manganelli D1, Palla A, Donnamaria V, Giuntini C. Clinical features of pulmonary embolism. Doubts and certainties. Chest. 1995;107(1 Suppl):25S-32S.

4. Meneveau N1, Ming LP, Séronde MF, Mersin N, Schiele F, Caulfield F, Bernard Y, Bassand JP. In-hospital and longterm outcome after sub-massive and massive pulmonary embolism submitted to thrombolytic therapy. Eur Heart J. 2003;24(15):1447-54.

5. Rumpf TH1, Krizmaric M, Grmec S. Capnometry in suspected pulmonary embolism with positive D-dimer in the field. Crit Care. 2009;13(6):R196. doi: 10.1186/cc8197. 